\title{
Familial pericentric inversion of chromosome 18: behavioral abnormalities in patients heterozygous for either the dup(18p)/del(18q) or dup(18q)/ del(18p) recombinant chromosome
}

\author{
Stefan J Vermeulen* ${ }^{1}$, Frank Speleman ${ }^{1}$, Leen Vanransbeeck ${ }^{1}$, Jasmien Verspeet ${ }^{1}$, \\ Björn Menten ${ }^{1}$, Marie-Rose Verschraegen-Spae ${ }^{1}$, Philippe De Wilde ${ }^{1}$, Ludwine Messiaen ${ }^{1}$, \\ Ron C Michaelis ${ }^{2}$ and Jules G Leroy ${ }^{1,2}$ \\ ${ }^{1}$ Center for Medical Genetics, OK5, Ghent University Hospital, Ghent, Belgium; ${ }^{2}$ Greenwood Genetic Center, \\ Greenwood, SC, USA
}

We describe a family in which the largest hitherto reported pericentric inversion of chromosome 18, inv(18)(p11.22q23), segregates. Individuals heterozygous for the nonrecombinant inversion were unaffected. However, those heterozygous for either the dup(18p)/del(18q) or $\operatorname{dup}(18 q) / \operatorname{del}(18 p)$ recombinant exhibited mild learning difficulty, personality disorders and deficient social behavior in the absence of mental retardation. Of the three family members tested, the behavioral abnormalities were more prominent in the two individuals with the $\operatorname{dup}(18 p) / \operatorname{del}(18 q)$ recombinant than in the one with the $\operatorname{dup}(18 q) / \mathrm{del}(18 p)$ recombinant. Genetic counseling issues for this family, in particular for the affected, include the enhanced probability of reduced fertility as well as the recurrence risk of the parental inversion equaling $1 / 2$ in surviving offspring. This observation kindles the interest in determining the frequency of subtelomeric rearrangements in individuals with learning difficulty and deficiency in social interaction, phenotypic features often considered to be of multifactorial causation.

European Journal of Human Genetics (2005) 13, 52-58. doi:10.1038/sj.ejhg.5201281

Published online 6 October 2004

Keywords: recombinant chromosome 18; learning deficit; social interaction deficit; mild phenotype

\section{Introduction}

Partial duplication-deletion aneusomy of the subtelomeric ends of chromosome 18 due to meiotic recombination within a pericentric inversion remains a rare observation in human beings. Most reports have involved recombinant terminal duplications and deletions large enough to be readily detectable in standard G-banded metaphases, and many have not included any higher-resolution molecular

*Correspondence: Dr SJ Vermeulen, Center for Medical Genetics, 0K5, Ghent University Hospital, De Pintelaan 185, B-9000 Ghent, Belgium. Tel: + 32-9-240-50-26; Fax: + 32-9-240-49-70;

E-mail: stefan.vermeulen@UGent.be

Received 11 March 2004; revised 17 June 2004; accepted 5 August 2004 cytogenetic studies. ${ }^{1-13}$ The majority of families were ascertained through the familial occurrence of patients with mental retardation/multiple congenital anomaly (MR/MCA) syndromes with features similar to the $18 \mathrm{p}$ and/or 18q terminal deletion syndromes. In some of the more severely affected patients, malformations such as lethal congenital adenomatoid malformation of the lung ${ }^{13}$ and alobar holoprosencephaly ${ }^{11}$ have been reported.

We report the clinical, psychological, cytogenetic and molecular findings in a family in which three members are heterozygous for dup/del-derivative chromosomes resulting from a large pericentric inversion, inv(18)(p11.22q23). The phenotypic consequences in the inversion recombinants were learning deficits, anxiety, depression and 
difficulties in social interaction. It is also interesting to note that the patients exhibited no MR or dysmorphic features.

\section{Materials and methods Subjects}

The proband (see electronic supplementary information, eFigure 1a; Figure 1, VI.1) was the 16-year-old daughter and first child of healthy nonconsanguineous parents. The parents requested clinical and genetic counseling regarding a learning difficulty encountered in her first year of high school and the teachers' recommendation of future vocationally oriented training. She had finished regular grade school with difficulty and delay. The parents were also concerned about the putative cognitive and behavioral resemblance of their daughter to her paternal uncle. Except for a high degree of myopia, for which she wore corrective glasses, the proband had not previously had any significant health problems.

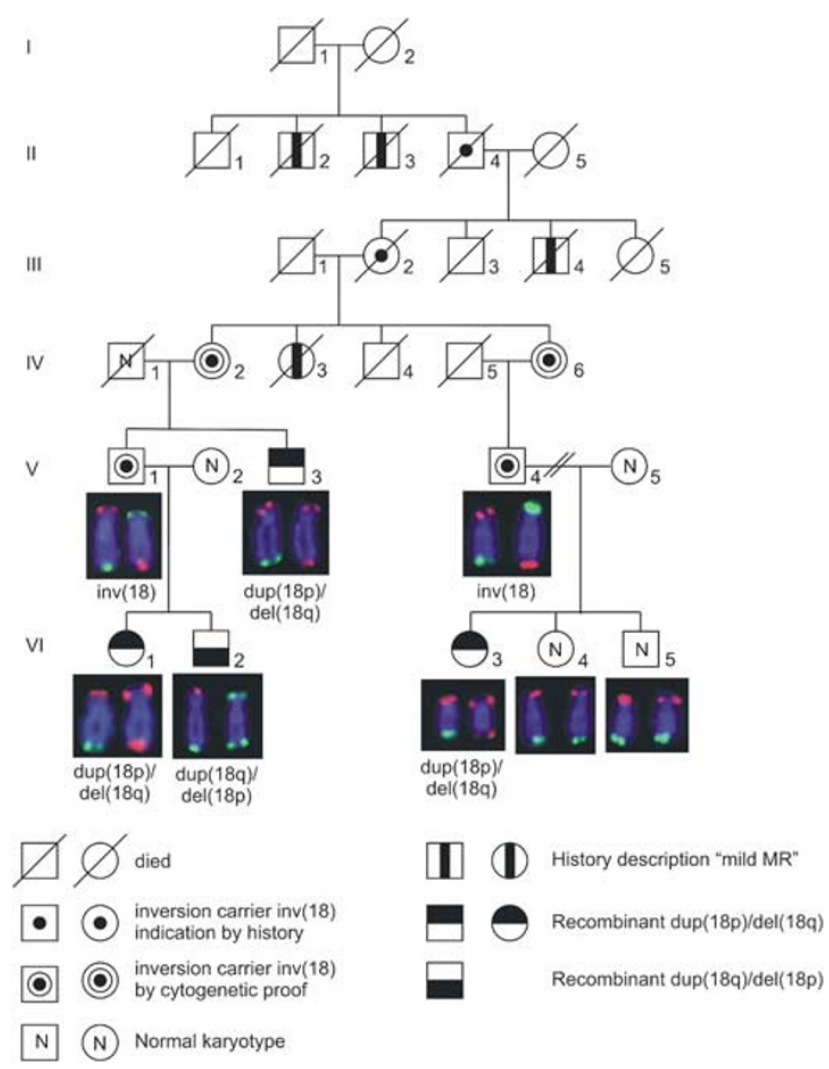

Figure 1 Family pedigree and representative partial FISH karyotypes. FISH performed using locus specific PAC probes: GS-52-M11 (18pter, spectrum orange) and GS964-M9 (18qter, spectrum green). The normal chromosome 18 is depicted on the left, the aberrant chromosome 18 on the right. $\operatorname{Inv}(18) ; \mathrm{V} .1$ and $\mathrm{V} .4$, recombinant dup(18p)/del(18q) in VI.1, V.3 and VI.3 and dup(18q)/ del(18p) in VI.2. The karyotype is normal in VI.4 and VI.5.
The proband's brother, aged 14 years, was physically healthy (see electronic supplementary information, eFigure1b; Figure 1, VI.2). He had consistently obtained near-average overall results in school, albeit with much help from the parents. His parents expressed concern about his social interaction skills. The proband and her brother approved the reproduction of their pictures.

Information provided mainly by the parents (Figure 1, V.1 and V.2) and by the proband's paternal grandaunt (Figure 1, IV.6) allowed construction of the family pedigree. Physical abnormalities were not recorded in any family member in any generation except for a moderate degree of myopia in the proband's brother and paternal uncle (V.3). High-degree myopia had also been present in IV.3, but was absent in IV.6 and her descendants. The individuals III.3, III.5 and IV.4 died in early childhood from unknown causes. The individuals II.2, II.3 and III. 4 were known in the family as 'mildly retarded' persons. All informants agreed that III.2, who had died in her 80s, was a physically and cognitively normal person. Her daughter (IV.3) had a weak, withdrawn and anxious personality and was thought to have mild MR. She was dependent on her mother's care and support, and died within 6 months after the passing of her mother. All descendants of IV.6 were at least college level graduates, except VI.3 who had learning difficulties and variant behavior. Fluorescence in situ hybridization (FISH) studies were performed in all surviving family members.

\section{Psychometric and personality testing}

As a quantitative psychometric test instrument the Dutch version of the Wechsler Adult Intelligence Scale, edition III (WAIS-III) was used (see supplementary information). In addition, a number of qualitative behavior and personality test instruments were used: the Symptom Checklist 90 (SCL-90), the Nijmegen Personality Questionnaire (NPQ), the State Trait Anxiety Inventory (STAI), the Social Anxiety Inventory (SAI), the Utrecht Coping Questionnaire (UCQ) and the revised Beck Depression Inventory (BDI) (see supplementary information).

\section{Cytogenetic and molecular investigations}

Analysis of G-banded prometaphase chromosomes was performed on short-term lymphocyte cultures using standard procedures. ${ }^{14}$ FISH, microsatellite analysis and breakpoint mapping were performed essentially as described in the supplementary information.

\section{Results}

\section{Clinical examinations}

At the age of 16 years, the proband's height was $165 \mathrm{~cm}$ (p50-p75) (see electronic supplementary information, eFigure 1a; Figure 1, VI.1). Her occipetal frontal circumfer- 
ence (OFC) was $51.3 \mathrm{~cm}$ (about p3). She weighed $45.3 \mathrm{~kg}$ (p3-p10). She wore corrective glasses for high-grade myopia $(-12 \mathrm{D})$, but otherwise showed neither physical nor neurological abnormalities. Her cooperation was excellent. Both parents were clinically normal and healthy. Neither had any grade of myopia. The OFC was $54.3 \mathrm{~cm}$ in the mother and $57.5 \mathrm{~cm}$ in the father.

The proband's brother (see electronic supplementary information, eFigure 1b; Figure 1, VI.2) was examined at the age of 14 years. His height was $167 \mathrm{~cm}$ (p50-p75), OFC was $55.0 \mathrm{~cm}$ and he weighed $50.3 \mathrm{~kg}$ (p50). Except for adequately corrected mild myopia, he was found to be physically normal. Although the parents did not compare his personality to that of his paternal uncle, they expressed concern mainly about his less than adequate skills in social interaction with his peers.

The paternal uncle (Figure 1, V.3) had an OFC of $56.5 \mathrm{~cm}$ but was not fully examined clinically. He had no physical or neurological abnormalities. All other subjects available for study were found to be physically and cognitively normal by at least one of the authors (JGL). None of the patients showed any dysmorphic features; in particular, proximally implanted thumbs and narrow ear canals were not observed.
Characterization of chromosome 18 rearrangements Upon G-banding the proband (see electronic supplementary information, eFigure 1a; Figure 1, VI.1) was found to have a small additional band at the distal end of $18 \mathrm{q}$ (Figure 2e). In order to determine the nature of the rearrangement and the origin of the additional material in 18qter, karyotyping of both parents was performed. The mother's (Figure 1, V.2) karyotype was normal, while in the father (Figure 1, V.1; Figure 2B) the banding analysis suggested the presence of a large, and apparently balanced, pericentric inversion of chromosome 18. Hence, his karyotype was tentatively described as 46,XY, inv(18)(p11.22q23). Subsequent FISH analyses using chromosome 18 paint, the subtelomeric YAC probe HTY3045 (Figure 2c) and PAC probes from the subtelomeric regions of $18 \mathrm{p}$ and $18 \mathrm{q}$ confirmed the inversion in the father.

In the proband, the derivative chromosome 18 was shown to bear a duplication of the distal 18p segment and a deletion of the distal $18 \mathrm{q}$ region. For an overview of all karyotypes, see Table 1 . In order to assess the size of the noninverted distal segments of chromosome 18 FISH was performed with a $1 \mathrm{Mb}$ probe set. Probe RP11-146G7 (bp $6752909-6933645$ on $18 \mathrm{p}$ ) was found to be present at both ends of the proband's chromosome 18, and is therefore
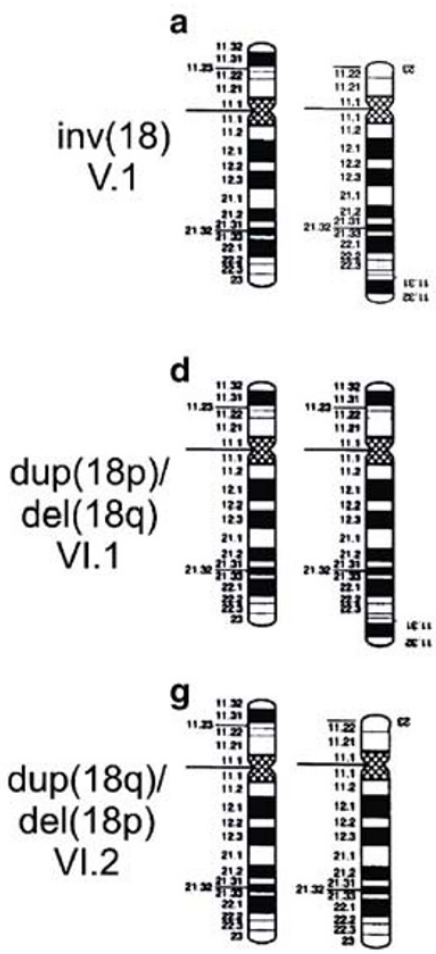

b
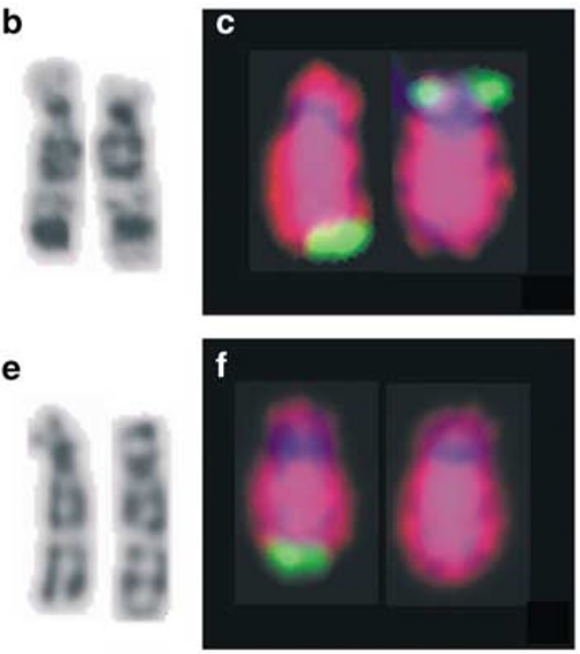

h

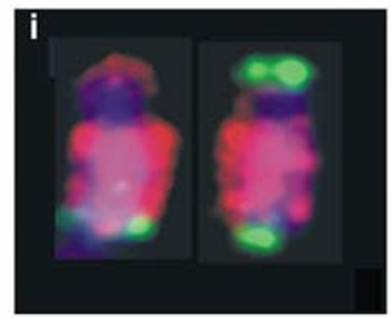

Figure 2 Ideograms of chromosome $18(\mathbf{a}, \mathbf{d}, \mathbf{g})$, representative G-banded partial karyotypes (b, e, h) and FISH results (c, f, i) with the use of the YAC probe HTY3045 (18qter, spectrum green) and a chromosome paint (spectrum red). The normal chromosome 18 is depicted on the left, the aberrant chromosome 18 on the right in each instance. Inv(18) in subject $V .1$ $(\mathbf{a}-\mathbf{c}) ; \operatorname{dup}(18 p) / \operatorname{del}(18 q)$ in proband VI.1 (d-f); dup(18q)/del(18p) in VI.2 (g-i). 
Table 1 Clinical and cytogenetic data in selected subjects in family with pericentric inversion chromosome 18: Karyotypephenotype correlation.

\begin{tabular}{|c|c|c|c|c|}
\hline Pedigree \# & Relation to proband & Karyotype & $\begin{array}{l}\text { Cytogenetic } \\
\text { designation }\end{array}$ & $\begin{array}{l}\text { Clinical } \\
\text { Phenotype }^{\mathrm{a}}\end{array}$ \\
\hline $\begin{array}{l}\text { VI.1 } \\
\text { (proband) }\end{array}$ & - & $46, X X, \operatorname{rec}(18) \operatorname{dup}(18 p) \operatorname{inv}(18)(p 11.22 q 23)$ & $\operatorname{dup}(18 p) / \operatorname{del}(18 q)$ & $\mathrm{V}$ \\
\hline VI. 2 & Brother & $46, X Y, \operatorname{rec}(18) \operatorname{dup}(18 q) \operatorname{inv}(18)(p 11.22 q 23)$ & $\operatorname{dup}(18 q) / \operatorname{del}(18 p)$ & $\mathrm{V} !$ \\
\hline V.1 1 & Father & $46, X Y, \operatorname{inv}(18)(p 11.22 q 23)$ & $\operatorname{inv}(18)$ & $\mathrm{nl}$ \\
\hline V.2 & Mother & $46, x \times$ & $\mathrm{nl}$ & $\mathrm{nl}$ \\
\hline V.3 & Pat uncle & $46, X Y, \operatorname{rec}(18) \operatorname{dup}(18 p) \operatorname{inv}(18) p 11.22 q 23)$ & $\operatorname{dup}(18 p) / \operatorname{del}(18 q)$ & V \\
\hline IV.1 & Pat grandfather & $46, X Y$ & $\mathrm{nl}-1$ & $\mathrm{nl}^{\mathrm{b}}$ \\
\hline IV.2 & Pat grandmother & $46, X X, \operatorname{inv}(18)(p 11.22 q 23)$ & $\operatorname{inv}(18)$ & $\mathrm{nl}$ \\
\hline IV.6 & Pat grandaunt & $46, X X, \operatorname{inv}(18)(\mathrm{p} 11.22 \mathrm{q} 23)$ & $\operatorname{inv}(18)$ & $\mathrm{nl}$ \\
\hline V.4 & Pat third degree relative & $46, X Y, \operatorname{inv}(18)(\mathrm{p} 11.22 \mathrm{q} 23)$ & $\operatorname{inv}(18)$ & $\mathrm{nl}$ \\
\hline VI. 3 & Pat second cousin & $46, X X, \operatorname{rec}(18) \operatorname{dup}(18) \operatorname{inv}(18)(p 11.22 q 23)$ & $\operatorname{dup}(18 p) / \operatorname{del}(18 q)$ & $\mathrm{V}^{\text {nt }}$ \\
\hline VI.4 & Pat second cousin & $46, X X$ & $\mathrm{nl}-12$ & $\mathrm{nl}$ \\
\hline VI.5 & Pat second cousin & $46, X Y$ & $\mathrm{nl}$ & $\mathrm{nl}$ \\
\hline
\end{tabular}

$\mathrm{nl}$ : clinically normal; $\mathrm{V}$ : variant behavior; Pat.: paternal.

${ }^{a}$ For description of phenotypes, see text.

${ }^{\mathrm{b}}$ Deceased since karyotyping. V!: phenotype not discernable objectively from $\mathrm{V}$ by psychologic study; $\mathrm{V}^{\text {nt: }}$ : not available for either psychometric and personality testing.

distal to the inversion breakpoint. Probe RP11-51B9 (bp $7878630-8036438$ on $18 \mathrm{p}$ ) was present in one copy only in the rec(18), on the short arm, and is therefore proximal to the inversion breakpoint.

The 18q23 breakpoint was mapped distal to probe RP11$234 \mathrm{~N} 1$ (bp $72264534-72443247$ on 18qter) and proximal to RP11-118I2 (bp 73602957-73762161 on 18qter). RP11$118 \mathrm{I} 2$ was found at neither end of the proband's recombinant chromosome 18 , but was detected at both ends of the recombinant chromosome 18 in her brother. From these results, the size of the $18 \mathrm{p}$ subtelomeric fragment involved in the recombination was estimated to be approximately $8 \mathrm{Mb}$, whereas the $18 \mathrm{q}$ subtelomeric fragment was estimated to be approximately $3 \mathrm{Mb}$ in size. Similar investigations (Figure 1 and Table 1) showed subsequently that the paternal uncle's (V.3) karyotype harbored the same recombinant dup(18p)/del(18q) chromosome as was found in the proband. A 'non-recombinant' inversion chromosome 18 was subsequently found in the proband's paternal grandmother (IV.2) and in her paternal grandaunt (IV.6) and also in the only son (V.4) of the latter. Upon the request of the paternal grandaunt (IV.6) the three offspring of her son, subject V.4, were also studied. In the oldest daughter (VI.3) the recombinant chromosome $\operatorname{dup}(18 \mathrm{p}) / \operatorname{del}(18 \mathrm{q})$ was found. In the two younger sibs, the karyotype was normal (Figure 1 and Table 1).

Microsatellite analysis confirmed the findings of the cytogenetic studies (see electronic supplementary information, eFigure 2).

\section{Psychometric testing (see also electronic} supplementary information)

Scores on all tests were noticeably lower in the two individuals with the $\operatorname{dup}(18 \mathrm{p}) / \operatorname{del}(18 \mathrm{q})$ recombinant chro- mosome than in the subject with the dup(18q)/del(18p) recombinant (see electronic supplementary information, eTable 1). The parents both scored within normal limits in the psychometric and personality tests applied to the affected.

In both the proband and her uncle, FSIQ, VIQ and PIQ were within the normal range. Working memory, processing speed scored significantly below average as was the case in both subject accumulation and verbal arithmetic subtests. The PSI score of the proband's uncle was the only cognitive score that fell below the normal range. Attention deficit and often failing audiogenic memory were also recorded for the uncle. In addition, some subtest scores as well as direct observation suggested that the uncle was dyslexic. The proband's brother had FSIQ and VIQ scores close to the population average. However, like his sister and uncle, his PIQ was significantly below his VIQ score. In some verbal arithmetic subtests (results not shown) he scored much below his FSIQ profile. Thinking in logical sequence was often problematic and logical thinking using numbers often insurmountable.

Information obtained by family history pointed to similar learning difficulty in the proband's second cousin (Figure 1, VI.3), who also has the $\operatorname{dup}(18 \mathrm{p}) / \operatorname{del}(18 \mathrm{q})$ recombinant chromosome but was not available for psychometric testing.

\section{Behavioral and personality testing}

The proband's behavioral phenotype is marked by significant anxiety and intense stress associated with social interactions. On the STAI, she scored in the seventh decile on the trait anxiety scale and the ninth decile on the state anxiety scale. The test results schowed a further increase in her anxiety level in the face of social interactions and other 
external events. Consistent with this, she scored high on the social incompetence scale and very high on the hostility/mistrust scale of the NPQ. On the IOA, she scored high to very high on the social anxiety subscales related to initiating conversation, giving compliments and asking attention for one's own opinion, and scored in the midrange on the subscale pertinent to giving critical remarks to others.

In addition the proband also scored high on the SCL-90 depression scale and indicated a high incidence of depressive reactions when coping with stressful events by the UCQ. It should be noted that these scores contradict her mild score on the BDI. However, in all three individuals the BDI scores were consistently lower than the other indices of depression. In addition to anxiety and depression related to social interaction significant mental disorganization was revealed in the personality profile. She scored high on scales of psychoneurosis and mental disorganization in the SCL-90, and very high on the mental instability scale of the NPQ.

The proband's uncle's personality was marked most prominently by depression and to a lesser degree by moderate anxiety. In stressful events, his score on the BDI indicated less depression than his score on other instruments. However, his BDI score (moderate depression) was significantly higher than those of his niece and nephew.

The uncle's personality testing scores indicated moderate to high levels of anxiety, but little if any increased stress in the face of social interactions. Irrespective of the high score of the several tests applied, this person had almost no subjective difficulty upon engaging in social interactions. In spite of the relative ease with which this subject engaged in social interaction, he had a history also of dysfunctional relationships with coworkers, acquaintances and relatives. His lack of success in social interactions may have been due to his high level of psychoneurosis and mental disorganization. The SCL-90 indicated very high levels of both these traits, and he scored high on the mental instability scale of the NPQ.

Mental organization was better in the proband's brother, who was more at peace with himself than his sister or uncle. Unlike the latter, the brother's score on the personal inadequacy scale of the NPQ was average and his level of self-contentment was high. However, the results of the personality tests were somewhat inconsistent in him. Although he scored high on the depression and anxiety scales of the SCL-90, he showed minimal depression according to the BDI, and obtained a midrange score regarding the incidence of depressive coping reactions in the face of stressful events.

In spite of this relative self-contentment, the brother's feelings of social incompetence were strong. In addition, he was highly agoraphobic and scored very high on the hostility and mistrust scales of the SCL-90 and the NPQ.
Inconsistent scores for the level of stress in the face of social interactions were obtained. According to the SAI, initiating conversation, requesting attention for his own opinion and criticizing others were only mildly stressful. In contrast, expressing appreciative thoughts of himself or of others was very stressful. His coping with stressful events was often highly emotional (UCQ). In spite of his apparently adequate level of mental organization, high overall levels of psychoneurosis were detected by the SCL-90.

\section{Discussion}

This report describes the largest pericentric inversion of chromosome 18 reported to date. It segregated through at least four generations and was transmitted by the normal inversion carriers either as the unaltered inversion or as one of two alternate recombinants. The phenotype observed is of interest for two reasons. First, the mild phenotype would not have satisfied the current criteria put forward in order to select patients for subtelomeric FISH studies. ${ }^{15}$ Neither MR, facial dysmorphism, congenital developmental anomalies, nor prenatal or postnatal growth disturbance were observed. Subtelomeric rearrangements have been reported in approximately $5 \%$ of patients with moderate to severe MR and facial dysmorphism and in about $0.5 \%$ of patients with mild MR. ${ }^{16-24}$ Secondly, contrary to the patients in this report, the large majority of patients heterozygous for a recombinant inverted chromosome 18 reported in the literature had severe MR/MCA with severe clinical morbidity and often with early lethal outcome. $^{1-10,25}$ In one instance holoprosencephaly (HPE11), in another congenital cystic adenomatoid malformation of the lungs was diagnosed prenatally. ${ }^{13}$ In all these instances, either one or both breakpoints were closer to the centromere than the breakpoint locations observed in this family (Figure 3). Hence, the resulting structural aneuploidy was considerably larger and the pathological implications in the recombinants more prominent. In only one literature report, ${ }^{12}$ one $\operatorname{dup}(18 q) / \operatorname{del}(18 p)$ recombinant with a rather mild phenotype and two dup(18p)/ del(18q) recombinants with severe phenotype were described in a single family (Figure 3). In the former minor dysmorphic features, small stature and obesity were observed. Learning difficulty was noticed only after the first year of primary school and a cognitive delay of 2 years recorded by psychometric testing at 8 years. Unfortunately, molecular breakpoint location was not available in the latter report. The large phenotypic difference between the two types of inversion chromosome 18 recombinants was most likely related to the large difference in the structural aneuploidy between them. The $\operatorname{dup}(18 \mathrm{q}) / \mathrm{del}(18 \mathrm{p})$ recombinant patient with the milder phenotype, the one with the smallest structural aneuploidy, shared partly the mild 


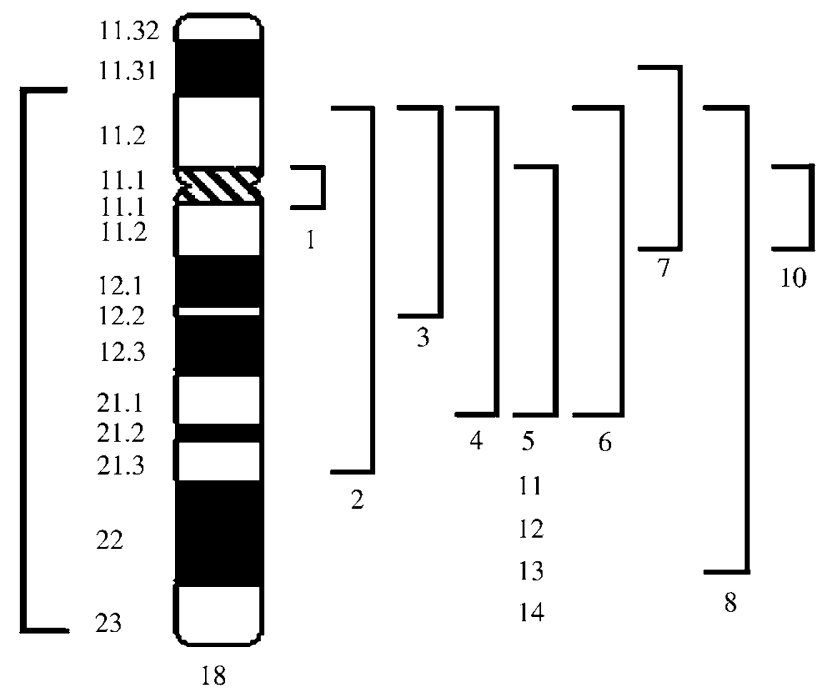

Figure 3 Ideogrammatic overview of reported familial occurrence of pericentric inversion 18 with segregating recombinants. Square bracket to the left of the chromosome indicates size and boundaries of the pericentric inversion in this report. Similar square brackets to the right of the figure represent size estimates in such inversion 18 reports in the literature; The roman numeral indicates the corresponding reference number: $1,,^{2} 2,{ }^{1} 3,,^{25} 4,,^{10} 5,{ }^{3} 6,{ }^{4}$ $7,{ }^{11} 8,{ }^{12} 10,511,612,713,814^{9}$.

clinical phenotype in the patients presented here. The main phenotypic deficiencies in our patients were in the domain of social interaction. These adverse effects were not found in any of the nonrecombinant inversion chromosome 18 carriers. The learning difficulty experienced during the school years by the two $\operatorname{dup}(18 p) / \operatorname{del}(18 q)$ individuals tested psychometrically (see electronic supplementary information, V.3 and VI.1) were probably related to their low average IQ. The learning difficulty in the subject with the dup(18q)/del(18p) recombinant chromosome (see electronic supplementary information; VI.2) with FSIQ scores equal to the population average, appeared to be related more to the variant personality characteristics. It is tempting to ascribe the phenotypic differences in either type of patient to the qualitatively different genetic imbalance. If such correlation is really observable it may be predicted that the $\operatorname{dup}(18 \mathrm{q}) / \operatorname{del}(18 \mathrm{p})$ karyotype encompassing the $8 \mathrm{Mb}$ 18pter deletion involving the region with more sparsely distributed genes ${ }^{26}$ and the $3 \mathrm{Mb}$ duplication of 18qter, would consistently produce the more mild phenotype. Similarly, the $\operatorname{dup}(18 p) / \operatorname{del}(18 q)$ karyotype comprising the alternate imbalance would be consistently associated with the more severe phenotype. However interesting, the differences actually observed may be fortuitous for several reasons: first, even when all three $\operatorname{dup}(18 p) / \operatorname{del}(18 q)$ patients would have been available for psychometric and personality testing, the small numbers precluded statistical evaluation; second, in addition to similarities also differences were recorded among the $\operatorname{dup}(18 p) / \operatorname{del}(18 q)$ subjects, some of which may or may not be related to differences in sex, age and/or experience in life; third, different generation and educational influences, early in life in particular, may blur personality and cognitive differences between the two types of recombinants; fourth, interference of genetic background, more specifically of the nonrecombinant inv 18 carrier parent as well as possible differences of imprinting cannot be ruled out. Three reports have documented patients with microscopically visible 18pter deletions and normal or borderline intelligence, similar to the patients presented. However, no personality testing was performed in any of the patients limiting the ability to compare specific phenotypic details. ${ }^{27-29}$ Genetic counseling to the family is particularly challenging for more than one reason. Empirical or experimental data regarding recurrence risk in offspring are not available. In this family, genetic counseling is of relevance to the recombinant inversion 18 subjects. The probability of transmitting the unaltered recombinant chromosome may well be as high as $50 \%$ of viable offspring, since it is likely that either inclusion of the normal or the recombinant chromosome is equally probable. In any event, genetic counseling must include offering prenatal cytogenetic testing of future pregnancies.

The phenotypic abnormalities observed in the individuals with either one or the other of the recombinant chromosomes are attributable to imbalances of genes located in the 18pter and/or 18qter regions rather than to position effects, as all nonrecombinant inversion heterozygotes in the family were physically and mentally normal. Thus at present, it is impossible to identify which terminal region gene(s) in the recombinant chromosome 18 is (are) mainly responsible for the variant phenotype. Our observation and the ones reported by Mejia-Baltodano et $\mathrm{al}^{12}$ are consistent with the consensus that the 18pter region contains a lower than average density of genes ${ }^{26}$ or at least a low number of candidate genes affecting development, maintenance and/or function of the central nervous system (CNS). Myelin basic protein (MBP) gene ge $^{30}$ and a gene structurally related to a phospholipid-transporting ATPase $(\mathrm{ATP9B})^{31}$ reside in the 18 pter region (see electronic supplementary information, eFigure 3 ). The products of either or both genes may be crucial for proper synthesis and/or maintenance of CNS myelin. The gene encoding the zinc-finger protein 236 (ZNF236) highly expressed in brain also resides in the 18qter region. ${ }^{32}$ Further studies may show whether mutations in these genes individually or combined adversely affect human interactive behavior, as may have been the case in our partially aneuploid patients. This observation, the initial step towards molecular elucidation of the rather mild behavioral disorders in the affected, may be helpful as well 
in defining the importance and role of structural aneuploidy in human so-called multifactorial disorders.

\section{Acknowledgements}

We thank The Wellcome Trust Sanger Institute (Hinxton, Cambridge, $U K)$ for providing us with the BAC probes for chromosome 18. The YAC probe HTY3045 was kindly provided by Dr A Jauch, Laboratory of Human Genetics, Heidelberg, Germany. This study is supported by Research Grants from the Fund for Scientific Research - Flanders (Belgium): 1.5.183.02, G.0200.03 and the Interuniversitary Attraction Poles Programme - Belgian Science Policy initiated by the Belgian State, Prime Minister's Office. The senior author (JGL) is indebted to the Center of Medical Genetics (chairperson: Dr Anne De Paepe), Ghent University Hospital, Ghent, Belgium and to the Greenwood Genetic Center (director: Dr Roger E Stevenson), Greenwood, SC, USA for the accommodation and academic support.

\section{References}

1 Asano T, Ikeuchi T, Shinohara T, Enokido H, Hashimoto K: Partial $18 \mathrm{q}$ trisomy and $18 \mathrm{p}$ monosomy resulting from a maternal pericentric inversion, inv(18)(p11.2q21.3). Jinrui Idengaku Zasshi 1991; 36: 257-265.

2 Andrews T, Gardiner AC, Boon AR: Recombinant chromosome 18 in two offspring of a chromosome 18 inversion heterozygote. Ann Genet 1982; 25: 185-188.

3 Jacobs PA, Melville M, Ratcliffe S, Keay AJ, Syme J: A cytogenetic survey of 11,680 newborn infants. Ann Hum Genet 1974; 37: $359-376$

4 Kukolich MK, Althaus BW, Sears JW, Mankinen CB, Lewandowski RC: Abnormalities resulting from a familial pericentric inversion of chromosome 18. Clin Genet 1978; 14: 98-104.

5 Teyssier JR, Bajolle F: Duplication-deficiency of chromosome 18, resulting from recombination of a paternal pericentric invesion, with a note for genetic counselling. Hum Genet 1980; 53: 195-200.

6 Turleau C, de Grouchy J: Trisomy 18qter and trisomy mapping of chromosome 18. Clin Genet 1977; 12: 361-371.

7 Vianna-Morgante AM, Nozaki MJ, Ortega CC, Coates V, Yamamura Y: Partial monosomy and partial trisomy 18 in two offspring of carrier of pericentric inversion of chromosome 18. J Med Genet 1976; 13: 366-370.

8 Vigi V, Maraschio P, Bosi G, Guerini P, Fraccaro M: Risk for recombinants in pericentric inversions of the (p11 leads to q21) region of chromosome 18. Hum Genet 1977; 37: 1-5.

9 Martin AO, Simpson JL, Deddish RB, Elias S: Clinical implications of chromosomal inversions. A pericentric inversion in No. 18 segregating in a family ascertained through an abnormal proband. Am J Perinatol 1983; 1: 81-88.

10 Israels T, Hoovers J, Turpijn HM, Wijburg FA, Hennekam RC: Partial deletion of $18 \mathrm{p}$ and partial duplication of $18 \mathrm{q}$ caused by a paternal pericentric inversion. Clin Genet 1996; 50: 520-524.

11 Leonard NJ, Tomkins DJ, Demianczuk N: Prenatal diagnosis of holoprosencephaly (HPE) in a fetus with a recombinant (18)dup(18q)inv(18)(p11.31q11.2)mat. Prenat Diagn 2000; 20: 947-949.

12 Mejia-Baltodano G, Bobadilla L, Gonzalez RM, Barros-Nunez P: High recurrence of recombinants in a family with pericentric inversion of chromosome 18. Ann Genet 1997; 40: 164-168.

13 Roberts D, Sweeney E, Walkinshaw S: Congenital cystic adenomatoid malformation of the lung coexisting with recombinant chromosome 18. A case report. Fetal Diagn Ther 2001; 16: 65-67.

14 Yunis JJ, Sawyer JR, Ball DW: The characterization of highresolution G-banded chromosomes of man. Chromosoma 1978; 67: 293-307.

15 de Vries BB, White SM, Knight SJ et al: Clinical studies on submicroscopic subtelomeric rearrangements: a checklist. J Med Genet 2001; 38: $145-150$.

16 Anderlid BM, Schoumans J, Anneren G et al: Subtelomeric rearrangements detected in patients with idiopathic mental retardation. Am J Med Genet 2002; 107: 275-284.

17 Baker E, Hinton L, Callen DF et al: Study of 250 children with idiopathic mental retardation reveals nine cryptic and diverse subtelomeric chromosome anomalies. Am J Med Genet 2002; 107: 285-293.

18 Clarkson B, Pavenski K, Dupuis L et al: Detecting rearrangements in children using subtelomeric FISH and SKY. Am J Med Genet 2002; 107: 267-274.

19 De Vries BB, Winter R, Schinzel A, van Ravenswaaij-Arts C: Telomeres: a diagnosis at the end of the chromosomes. J Med Genet 2003; 40: 385-398.

20 Flint J, Knight S: The use of telomere probes to investigate submicroscopic rearrangements associated with mental retardation. Curr Opin Genet Dev 2003; 13: 310-316.

21 Joyce CA, Dennis NR, Cooper S, Browne CE: Subtelomeric rearrangements: results from a study of selected and unselected probands with idiopathic mental retardation and control individuals by using high-resolution G-banding and FISH. Hum Genet 2001; 109: 440-451.

22 Knight SJ, Regan R, Nicod A et al: Subtle chromosomal rearrangements in children with unexplained mental retardation. Lancet 1999; 354: 1676-1681.

23 Riegel M, Baumer A, Jamar M et al: Submicroscopic terminal deletions and duplications in retarded patients with unclassified malformation syndromes. Hum Genet 2001; 109: 286-294.

24 Rio M, Molinari F, Heuertz S et al: Automated fluorescent genotyping detects $10 \%$ of cryptic subtelomeric rearrangements in idiopathic syndromic mental retardation. J Med Genet 2002; 39: $266-270$.

25 Ayukawa H, Tsukahara M, Fukuda M, Kondoh O: Recombinant chromosome 18 resulting from a maternal pericentric inversion. Am J Med Genet 1994; 50: 323-325.

26 Venter JC, Adams MD, Myers EW et al: The sequence of the human genome. Science 2001; 291: 1304-1351.

27 Babovic-Vuksanovic D, Jenkins SC, Ensenauer R, Newman DC, Jalal SM: Subtelomeric deletion of $18 p$ in an adult with paranoid schizophrenia and mental retardation. Am J Med Genet 2004 124A: $318-322$.

28 Tsukahara $\mathrm{M}$, Imaizumi K, Fujita K, Tateishi H, Uchida M: Familial Del(18p) syndrome. Am J Med Genet 2001; 99: 67-69.

29 Velagaleti GV, Harris S, Carpenter NJ, Coldwell J, Say B: Familial deletion of chromosome 18 (p11, 2)); Ann: Genet, 1996; 39: 201-204.

30 Keppler-Noreuil KM, Carroll AJ, Finley SC et al: Chromosome 18q paracentric inversion in a family with mental retardation and hearing loss. Am J Med Genet 1998; 76: 372-378.

31 Halleck MS, Pradhan D, Blackman C, Berkes C, Williamson P, Schlegel RA: Multiple members of a third subfamily of P-type ATPases identified by genomic sequences and ESTs. Genome Res 1998; 8: 354-361.

32 Holmes DI, Wahab NA, Mason RM: Cloning and characterization of ZNF236, a glucose-regulated Kruppel-like zinc-finger gene mapping to human chromosome 18q22-q23. Genomics 1999; 60: 105-109.

Supplementary Information accompanies the paper on European Journal of Human Genetics website (http://www.nature.com/ejhg). 